\title{
Asthma and occupation in the 1958 birth cohort
}

\author{
Rebecca Elisabeth Ghosh, ${ }^{1}, 2,3,4$ Paul Cullinan, ${ }^{2}$ David Fishwick, ${ }_{1}^{5}$ Jennifer Hoyle, ${ }^{6}$ \\ Chris J Warburton, ${ }^{7}$ David P Strachan, ${ }^{8}$ Barbara K Butland, ${ }_{1}^{8}$ Debbie Jarvis ${ }^{1}$
}

\begin{abstract}
- Additional material is published online only. To view please visit the journal online (http://dx.doi.org/10.1136/ thoraxjnl-2012-202151).
\end{abstract}

${ }^{1}$ Respiratory Epidemiology and Public Health Group, National Heart and Lung Institute, Imperial College London and MRC-HPA Centre for Environment and Health, Imperial College, London, UK ${ }^{2}$ Department of Occupational and Environmental Medicine, National Heart and Lung Institute, London, UK ${ }^{3}$ Department of Epidemiology and Biostatistics, Imperial College, London, UK ${ }^{4}$ MRC-HPA Centre for Environment and Health, Imperial College, London, UK ${ }^{5}$ Centre for Workplace Health, Sheffield, UK

${ }^{6}$ North Manchester General Hospital, Manchester, UK

${ }^{7}$ Aintree Chest Centre, University Hospital Aintree, Liverpool, UK

${ }^{8}$ Division of Population Health Sciences and Education, St George's, University of London, London, UK

\section{Correspondence to}

Dr Rebecca Elisabeth Ghosh, MRC-HPA Centre for Environment and Health, Imperial College London, St Mary's Campus, London W2 1PG, UK; r.ghosh@imperial.ac.uk

Received 11 May 2012 Revised 7 December 2012 Accepted 10 December 2012 Published Online First 21 January 2013

To cite: Ghosh RE, Cullinan P, Fishwick D, et al. Thorax 2013;68:365-371.

\begin{abstract}
Objective To examine the association of adult onset asthma with lifetime exposure to occupations and occupational exposures.
\end{abstract}

Methods We generated lifetime occupational histories for 9488 members of the British 1958 birth cohort up to age 42 years. Blind to asthma status, jobs were coded to the International Standard Classification of Occupations 1988 and an Asthma Specific Job Exposure Matrix (ASJEM) with an expert re-evaluation step. Associations of jobs and ASJEM exposures with adult onset asthma were assessed in logistic regression models adjusting for sex, smoking, social class at birth and childhood hay fever.

Results Of the 7406 cohort members with no asthma or wheezy bronchitis in childhood, 639 (9\%) reported asthma by age 42 years. Adult onset asthma was associated with 18 occupations, many previously identified as risks for asthma (eg, farmers: OR 4.26, 95\% Cl 2.06 to 8.80; hairdressers: OR 1.88, 95\% C 1.24 to 2.85; printing workers: OR $3.04,95 \% \mathrm{Cl} 1.49$ to 6.18). Four were cleaning occupations and a further three occupations were likely to use cleaning agents. Adult onset asthma was associated with five of the 18 high-risk specific ASJEM exposures (flour exposure: OR 2.12, 95\% Cl 1.17 to 3.85; enzyme exposure: OR 2.32, $95 \% \mathrm{Cl} 1.22$ to 4.42 ; cleaning/disinfecting products: OR $1.67,95 \% \mathrm{Cl} 1.26$ to 2.22 ; metal and metal fumes: OR $1.45,95 \% \mathrm{Cl} 1.02$ to 2.07 ; textile production: OR 1.71, $95 \% \mathrm{Cl} 1.12$ to 2.61$)$. Approximately $16 \%(95 \% \mathrm{Cl}$ $3.8 \%$ to $27.1 \%$ ) of adult onset asthma was associated with known asthmagenic occupational exposures.

Conclusions This study suggests that about $16 \%$ of adult onset asthma in British adults born in the late 1950s could be due to occupational exposures, mainly recognised high-risk exposures.

\section{INTRODUCTION}

Exposure to substances in the workplace is one of the known causes of asthma and over 350 occupational agents have been linked to adult onset asthma. These exposures account for $10-15 \%$ of new or recurrent cases in adulthood. ${ }^{12}$

Most information on the burden of occupational asthma in the UK is based on surveillance data or studies of specific occupational groups which may underestimate the risks. ${ }^{3}$ UK surveillance schemes and Health and Safety Executive figures have identified 'vehicle paint sprayers', 'bakers and flour confectioners' and the 'manufacture of basic metals or motor vehicles' as occupations with the highest rates of occupational asthma in the UK. ${ }^{4}{ }^{5}$ Exposure to isocyanates and flour/grain exposure are the most
Key messages

What is the key question?

- How much adult onset asthma is attributable to exposure to agents in the workplace?

What is the bottom line?

- Sixteen per cent of adult onset asthma in a large British cohort who have been followed from birth to middle age was explained by workplace exposures.

\section{Why read on?}

- Adult onset asthma was more common in those working in jobs with high-risk exposures. There was strong evidence of associations with working in cleaning jobs and in jobs likely to involve exposure to cleaning agents.

common reported identified causes of occupational asthma in the UK, ${ }^{6}$ but associations with metal working fluids, latex and laboratory animals ${ }^{4}$ have also been frequently recorded. More recently, cleaning and sterilising agents have been identified as a potential cause of asthma in countries outside the UK. Within the UK, cleaning products have been identified by surveillance schemes as a potential cause of occupational asthma, ${ }^{57}$ but the scale of the problem in the UK is unclear.

There have been no longitudinal population-based studies of occupational asthma conducted within the UK, although UK participants were included in large international initiatives. ${ }^{8}$ No large population-based birth cohort studies have examined the association of occupational exposure with work from entry to the workforce through to middle age. The aim of this analysis is to identify the major occupations and occupational exposures that are associated with asthma in the British adult population.

\section{METHODS}

\section{Study population}

The National Child Development Study is a longitudinal study following over 11000 people living in Great Britain. The original cohort consisted of 17638 babies born in Great Britain between 3 and 9 March 1958, with enrichment at ages 7, 11 and 16 with immigrants born outside the UK but born in the same week $(n=920)$. A full description of the cohort, its development and the response is available. ${ }^{9}$ 
Information on asthma or wheezy bronchitis was collected through interviews at ages $7,11,16,33$ and 42 years (in the first three surveys parents were questioned). At age 44-45 years participants underwent lung function testing (up to five attempts, standing, Vitalograph hand-held spirometer ${ }^{10}$ ). Serum total IgE was measured; where this was above the median $(30 \mathrm{kU} / \mathrm{l})$, serum-specific IgE to dust, cat and grass allergens was measured (HYTEC enzyme immunoassay).

At ages 33 and 42, trained interviewers collected short free text descriptions of jobs held by each participant to the age of 33 (maximum 12 jobs) or beyond (maximum 10 jobs). A job was defined as one lasting more than 1 month including parttime/temporary work but excluding education, training schemes, childcare or sickness/disability. Blind to asthma status, free text job titles and descriptions were coded to the International Standard Classification of Occupations (ISCO-88). ${ }^{11}$

Individual exposures were determined from the Asthma Specific Job Exposure Matrix (ASJEM). ${ }^{12}$ This assigns workplace exposure to 18 high-risk substances (nine high molecular weight (HMW) and five low molecular weight (LMW) antigens, three high-risk mixed environments and 'respiratory irritants'). The ASJEM classifies all other jobs as 'low-risk' or 'nonexposed', the former classification arising where the developers of the ASJEM considered that exposure to antigens was likely to be too low to provoke occupational asthma ('low antigen exposure') or where the exposure, although associated with respiratory disease, had not been clearly identified as a cause of asthma in the workplace at the time of the ASJEM development (eg, possible irritant exposures, combustion fumes, environmental tobacco smoke).

The ASJEM identifies and provides advice on jobs that should be re-evaluated ('expert judgement step'). This protocol ensures correct job coding from the free text descriptions of jobs provided by participants and improves the exposure assignment by examination of this free text and by incorporating expert knowledge (DF, JH and CJW) of local working practice. This step is conducted blind to asthma status.

\section{Statistical methods}

Participants who were reported to have ever had 'wheezy bronchitis' or 'asthma' (these two conditions could not be separated in the 16-year questionnaire) at any of the childhood surveys (7, 11 or 16 years) were excluded from analyses. Among the remainder, adult onset asthma was considered present if individuals reported that they 'ever had asthma' at ages 33 or 42. 'Adult asthma with airway obstruction' was considered present if a participant had adult onset asthma and a ratio of forced expiratory volume in $1 \mathrm{~s}$ to forced vital capacity $\left(\mathrm{FEV}_{1} / \mathrm{FVC}\right)$ $<70 \%$ based on highest $\mathrm{FEV}_{1}$ and FVC from up to five satisfactory blows at age 44-45.

The cross-sectional association of adult onset asthma by age 42 with current occupation (ISCO-88 code) and current ASJEM-defined exposure was investigated using logistic regression with adjustment for a priori potential confounders: sex, smoking as reported at age 42, father's social class (using 1951 Registrar General's Classification) and area of residence at age 42. We also adjusted for hay fever/allergic rhinitis in childhood as this is associated with choice of occupation in this cohort. ${ }^{13}$ For occupational groups in which there were sufficient cases $(>5)$, we corrected for multiple testing using the Simes procedure and generated q values by inverting multiple test procedures using the 'qqualue' package in STATA. ${ }^{14}$

Similar analyses exploiting the full occupational history were conducted to assess the association of adult onset asthma by the age of 42 years with ever having worked in each occupation (reference group all cohort members who had only worked in office-based occupations) or ever being exposed to asthmagenic agents (reference group all cohort members who had only worked in jobs that were classified by the ASJEM as 'nonexposed'). Lifetime exposure was considered in four mutually exclusive groups (none, low-risk only, high-risk only, high-rosk and low-risk). Exposure to each specific high-risk agent was considered in non-exclusive groups as few individuals had been exposed to only one specific agent through their working life. Low-risk exposures were also considered in non-exclusive groups but were additionally considered both with and without a lifetime high-risk exposure in order to observe any independent effect from having had a low-risk exposure.

Differences in duration of employment in the relevant occupation (or exposure) for those with and without adult onset asthma was tested using the Mann-Whitney U test.

The population attributable fraction (PAF) of life time occupational exposure for adult onset asthma was determined using the 'punaf' command in STATA (based on Greenland and Drescher ${ }^{15}$ ), within a single model that included adjustment for confounders.

Analyses were undertaken using STATA V.10 (College Station, Texas, USA).

\section{RESULTS}

After excluding 2082 cohort members with a parental report of asthma and/or wheezy bronchitis in childhood (at age 7, 11 or 16), the study sample contained 7406 individuals who had provided sufficient information at ages 33 and 42 to construct an occupational history from ages 16 to 42 .

Just under half were male $(46.7 \% \quad n=3456)$ and $24.1 \%$ $(n=1788)$ were smokers at the age of $42 \quad(30.5 \%$ were ex-smokers). The cumulative prevalence of adult onset asthma at age 42 was 9\% (639/7406). Lung function measurements at age 45 were available for 6188 of the 7406 participants, and the prevalence of adult onset asthma with airway obstruction was $2 \%(121 / 6188)$.

\section{Cross-sectional analysis}

At age 42, 87\% (6417/7406) of the sample were in some form of employment and 55\% (4093/7406) were in an office-based occupation (reference group for analysis of occupation). Having adult onset asthma at age 42 was more common in those who described themselves as being unemployed or sick/disabled (adjusted OR 2.67, 95\% CI 1.71 to 4.18 and OR 2.47, 95\% CI 1.72 to 3.55 , respectively) and as manufacturing labourers (ISCO code 9320) (adjusted OR 3.27, 95\% CI 1.55 to 6.93; $\mathrm{p}=0.014$ after correction for multiple testing). No other current occupations or ASJEM-defined exposures were associated with adult onset asthma (data not shown), even though current exposure to high-risk agents $(13 \%, \mathrm{n}=964)$ and low-risk agents $(24 \%, n=1772)$ was relatively common.

\section{Longitudinal analysis}

By age 42, 30\% (2217/7406) of the sample had only ever worked in an office-based occupation (the reference group). Participants with adult onset asthma had worked at some point in their life in one of 142 non-office-based occupations, but there were only 61 ISCO-coded occupations with at least five cases of adult onset asthma. Of the remaining 81 non-office-based occupations (23 with only one case), there were only two significant associations, both based on only two cases but, interestingly, both related to farming (7413-Dairy 
Table 1 Association of adult onset asthma with ever having worked in ISCO-coded occupation (61 occupations tested, 18 reaching conventional levels of significance)

\begin{tabular}{|c|c|c|c|c|c|c|c|c|c|c|}
\hline \multirow[b]{2}{*}{ Occupation } & \multicolumn{6}{|c|}{ Adult onset asthma } & \multicolumn{4}{|c|}{$\begin{array}{l}\text { Adult onset asthma with airflow } \\
\text { limitationt }\end{array}$} \\
\hline & Case/total & OR & $\mathrm{OR}^{*}$ & $95 \% \mathrm{Cl}$ & p Value & q Value & Case/total & $\mathrm{OR}^{*}$ & $95 \% \mathrm{Cl}$ & $\mathrm{p}$ Value \\
\hline Reference group & $170 / 2217$ & 1.00 & 1.00 & - & - & - & 29/1864 & 1.00 & - & \\
\hline 5122-Cooks & $42 / 367$ & 1.56 & 1.52 & 1.05 to 2.19 & 0.025 & 0.177 & $8 / 310$ & 1.45 & 0.64 to 3.24 & 0.372 \\
\hline 5123-Waiters, waitresses and bartenders & $78 / 667$ & 1.60 & 1.50 & 1.12 to 2.01 & 0.007 & 0.055 & $17 / 563$ & 1.64 & 0.88 to 3.08 & 0.122 \\
\hline 5133-Home-based personal care workers & $60 / 404$ & 2.10 & 1.94 & 1.40 to 2.69 & $<0.001$ & 0.002 & $11 / 355$ & 1.67 & 0.81 to 3.46 & 0.164 \\
\hline 5141-Hairdressers, barbers, beauticians & $32 / 218$ & 2.07 & 1.88 & 1.24 to 2.85 & 0.003 & 0.027 & $1 / 176$ & - & - & - \\
\hline 5169-Protective services workers & $14 / 130$ & 1.45 & 1.90 & 1.05 to 3.43 & 0.034 & 0.143 & 3/111 & - & - & - \\
\hline 6130-Market-oriented crop and animal producers & $10 / 57$ & 2.56 & 4.26 & 2.06 to 8.80 & $<0.001$ & 0.002 & $2 / 48$ & - & - & - \\
\hline 7232-Aircraft engine mechanics and fitters & $5 / 30$ & 2.41 & 3.81 & 1.41 to 10.31 & 0.008 & 0.056 & $1 / 27$ & - & - & - \\
\hline 7341-Compositors, typesetters & $10 / 60$ & 2.41 & 3.04 & 1.49 to 6.18 & 0.002 & 0.025 & $3 / 51$ & - & - & - \\
\hline 8263-Sewing machine operators & $19 / 133$ & 2.01 & 1.93 & 1.14 to 3.26 & 0.014 & 0.088 & $4 / 104$ & 1.92 & 0.64 to 5.73 & 0.243 \\
\hline 9130-Cleaners unspecified & $20 / 156$ & 1.77 & 1.58 & 0.95 to 2.63 & 0.078 & 0.234 & $2 / 125$ & - & - & - \\
\hline 9131-Domestic helpers and cleaners & $16 / 113$ & 1.99 & 1.79 & 1.02 to 3.14 & 0.044 & 0.154 & $3 / 91$ & - & - & - \\
\hline 9132-Helpers and cleaners in offices, hotels & $70 / 516$ & 1.89 & 1.82 & 1.34 to 2.48 & $<0.001$ & 0.002 & $17 / 431$ & 2.25 & 1.19 to 4.24 & 0.012 \\
\hline 9133-Hand-launderers and pressers & $8 / 50$ & 2.29 & 2.26 & 1.03 to 4.98 & 0.043 & 0.154 & - & - & - & - \\
\hline 9151-Messengers, package and luggage porters and deliverers & $12 / 103$ & 1.59 & 2.06 & 1.09 to 3.90 & 0.026 & 0.117 & $2 / 87$ & - & - & - \\
\hline 9152-Doorkeepers, watchpersons & $13 / 82$ & 2.27 & 2.59 & 1.37 to 4.87 & 0.003 & 0.027 & $5 / 65$ & 5.00 & 1.81 to 13.85 & 0.002 \\
\hline 9313-Building construction labourers & $18 / 208$ & 1.14 & 1.92 & 1.12 to 3.27 & 0.017 & 0.097 & $3 / 176$ & - & - & - \\
\hline 9320-Manufacturing labourers & $30 / 198$ & 2.15 & 2.55 & 1.66 to 3.93 & $<0.001$ & 0.001 & $7 / 161$ & 2.86 & 1.20 to 6.81 & 0.017 \\
\hline 9322-Hand packers and other manufacturing labourers & $22 / 170$ & 1.79 & 1.66 & 1.02 to 2.70 & 0.040 & 0.154 & $9 / 126$ & 4.12 & 1.85 to 9.17 & 0.001 \\
\hline
\end{tabular}

Each effect estimate is from a separate model with the reference group being individuals who had always worked in office-based occupations. Note that the groups are not mutually exclusive and are not adjusted for exposure to any of the other agents in the table.

Bold type indicates conventional levels of statistical significance $(p<0.05)$.

The $q$ value corresponds to the minimum false discovery rate at which the test may be called significant $(q<0.05)$.

${ }^{*}$ Adjusted for sex, smoking, father's social class at birth, region and hay fever.

†Those with asthma but no airflow limitation were coded 'no' for this analysis.

ASJEM, Asthma Specific Job Exposure Matrix; ISCO, International Standard Classification of Occupations.

products workers and 8331-Motorised farm and forestry plant operators). Ever having worked in one of 18 of the 61 occupations with at least five cases was positively associated with adult onset asthma. The associated risks are shown in table 1.

Four occupations were in cleaning (ISCO codes 9130-9133) and a further three were likely to include work with cleaning agents (5122-Cooks, 5123-Waiters, waitresses and bartenders and 5133-Home-based personal care workers). Even after correction for multiple testing there was evidence that two of these seven cleaning-related occupations (9132-Helpers and cleaners in offices, hotels and 5133-Home-based personal care workers) were associated with adult asthma. A borderline significant association of asthma with 5123-Waiters, waitresses and bartenders $(q=0.055)$ was also present after correction for multiple testing.

Occupations previously reported to cause asthma in adults (5141-Hairdressers, barbers, beauticians, 7341-Compositors, typesetters and 6130-Market-oriented crop and animal producers) were associated with adult onset asthma in this study, as were two previously unreported occupations (5169-Protective services workers and 9152-Doorkeepers, watchpersons).

Four of the 18 occupations associated with adult onset asthma were also significantly associated with asthma with airflow limitation. In general, the risk estimates increased with this definition, although the CIs were wider due to the smaller number of cases.

Participants with adult onset asthma who had ever worked in nine of the occupations in table 1 had spent less time working in these occupations than those without asthma (see online supplementary table E1). This difference was most marked for those ever working as 5133-Home-based personal care workers (median duration in people with asthma 1.88 years; in people without asthma 3.18 years; $\mathrm{p}=0.016)$, 9131-Domestic helpers and cleaners (1.08 years and 3.14 years, respectively; $p=0.022$ ) or 9322-Hand packers and other manufacturing labourers ( 0.63 years and 1.59 years, respectively; $p=0.011)$. In contrast, for 9313-Building construction labourers the median duration in people with asthma was 5.42 years and in people without asthma 1.36 years $(\mathrm{p}=0.009)$.

\section{ASJEM exposures}

By age 42 one-quarter (1864/7406) of participants had only ever worked in an occupation that was considered by the ASJEM to be 'non-exposed'; 595 (8\%) had been exposed to high-risk agents only, 2087 (28\%) to low-risk agents only and 2542 (34\%) had been exposed to both low-risk and high-risk agents.

Having ever been exposed to high-risk agents was associated with a higher risk of adult onset asthma irrespective of whether low-risk exposures had occurred (table 2). For those who had been exposed only to low-risk agents in their working life, there was no evidence of an increased risk of asthma $(p>0.05)$. The association of asthma with airflow limitation with these exposures was broadly similar although failed to reach conventional levels of significance. When those exposed to high-risk agents were compared with a reference group that included both 'nonexposed' and 'only exposed to low-risk agents', there was still evidence of an increased risk of adult onset asthma (adjusted OR 1.26 , 95\% CI 1.06 to 1.49 ).

Table 3 shows the risk of adult onset asthma with having ever been exposed to each of the main high-risk exposure groups included in the ASJEM. These estimates, from separate models 
Table 2 Associations between adult onset asthma and ever working in a mutually exclusive ASJEM exposure risk group by age 42

\begin{tabular}{|c|c|c|c|c|c|c|c|c|c|}
\hline \multirow[b]{2}{*}{ Exposure group } & \multirow[b]{2}{*}{ Case/totalt } & \multicolumn{4}{|c|}{ Adult onset asthma } & \multicolumn{4}{|c|}{ Adult onset asthma with airflow limitation‡ } \\
\hline & & OR & OR* & $95 \% \mathrm{Cl}$ & p Value & Case/totalt & OR* & $95 \% \mathrm{Cl}$ & p Value \\
\hline Non-exposed & $147 / 1864$ & 1.00 & 1.00 & - & - & $24 / 1567$ & 1.00 & - & - \\
\hline Ever a low-risk exposure (but never a high-risk) & $163 / 2087$ & 0.99 & 1.20 & 0.94 to 1.52 & 0.147 & 29/1701 & 1.21 & 0.69 to 2.13 & 0.497 \\
\hline Ever a high-risk exposure (but never a low-risk exposure) & $66 / 595$ & 1.46 & 1.53 & 1.12 to 2.09 & 0.007 & $10 / 484$ & 1.31 & 0.62 to 2.80 & 0.472 \\
\hline Worked in both low-risk jobs and in high-risk jobs & $235 / 2542$ & 1.19 & 1.34 & 1.07 to 1.68 & 0.010 & $48 / 2131$ & 1.48 & 0.89 to 2.47 & 0.131 \\
\hline
\end{tabular}

that do not include adjustment for co-exposure to other agents, identify five individual high-risk exposures that are significantly related with adult onset asthma (flour, antigenic enzymes, cleaning, metal fumes and textiles). LMW reactive cleaning products was the only association to remain significant after correction for multiple testing $(\mathrm{q}<0.000)$, although associations with flour and textile production were very close to significance $(q=0.053)$. Associations did not appear to be modifed by sex, smoking or atopy (see online supplementary tables E2-4). Asthma with airflow obstruction was associated with these five high-risk exposures. Associations were particularly strong for ever being exposed to HMW flour-associated antigens and HMW antigenic enzymes. The duration of employment in occupations with exposures associated with asthma was shorter for those with adult onset asthma (see online supplementary table E5).

Table 4 shows the association of adult onset asthma with exposure to the individual low-risk exposures while taking account of exposure to high-risk agents. There was no independent association

Table 3 Association of adult onset asthma with ever having worked in a high-risk exposure group by age 42

\begin{tabular}{|c|c|c|c|c|c|c|c|c|c|c|}
\hline \multirow[b]{2}{*}{ Exposure group } & \multirow[b]{2}{*}{ Case/total } & \multicolumn{5}{|c|}{ Adult onset asthma } & \multicolumn{4}{|c|}{$\begin{array}{l}\text { Adult onset asthma with airflow } \\
\text { limitationt }\end{array}$} \\
\hline & & OR & $\mathrm{OR}^{*}$ & $95 \% \mathrm{Cl}$ & $\mathrm{p}$ Value & q Value & Case/total & $\mathrm{OR}^{*}$ & $95 \% \mathrm{Cl}$ & p Value \\
\hline \multicolumn{11}{|l|}{ Main categories of high-risk exposures } \\
\hline Reference group (always worked in non-exposed) & $147 / 1864$ & 1.00 & 1.00 & - & - & - & 24/1567 & 1.00 & - & - \\
\hline Any exposure to HMW & $183 / 1897$ & 1.26 & 1.33 & 1.05 to 1.68 & 0.018 & N/A & $37 / 1593$ & 1.45 & 0.86 to 2.47 & N/A \\
\hline Any exposure to LMW & $189 / 1966$ & 1.25 & 1.49 & 1.18 to 1.89 & 0.001 & N/A & $37 / 1637$ & 1.51 & 0.88 to 2.59 & N/A \\
\hline Any exposure to mixed environments $t$ & $75 / 807$ & 1.21 & 1.45 & 1.07 to 1.97 & 0.016 & N/A & $19 / 669$ & 1.86 & 0.99 to 3.50 & N/A \\
\hline High probability of accidental peak exposure to irritants & $18 / 328$ & 0.68 & 1.05 & 0.62 to 1.77 & 0.870 & N/A & $4 / 269$ & 1.19 & 0.39 to 3.63 & N/A \\
\hline \multicolumn{11}{|c|}{ Subcategories of high-risk exposures } \\
\hline \multicolumn{11}{|l|}{ High molecular weight } \\
\hline HMW animal antigens & $21 / 249$ & 1.08 & 1.26 & 0.77 to 2.06 & 0.353 & 0.441 & $5 / 212$ & 1.48 & 0.55 to 4.01 & 0.442 \\
\hline HMW fish/shellfish antigens & $3 / 24$ & - & - & - & - & & - & - & - & - \\
\hline HMW flour associated antigens & $14 / 111$ & 1.70 & 2.12 & 1.17 to 3.85 & 0.014 & 0.053 & $6 / 81$ & 5.48 & 2.12 to 14.20 & 0.000 \\
\hline HMW plant other associated antigens & $21 / 225$ & 1.21 & 1.54 & 0.94 to 2.52 & 0.085 & 0.142 & $5 / 188$ & 2.34 & 0.92 to 5.92 & 0.074 \\
\hline HMW mite and insect antigens & $30 / 255$ & 1.57 & 1.38 & 0.90 to 2.12 & 0.137 & 0.187 & $7 / 211$ & 1.79 & 0.75 to 4.31 & 0.192 \\
\hline HMW antigenic enzymes & $12 / 90$ & 1.81 & 2.32 & 1.22 to 4.42 & 0.010 & 0.053 & $5 / 64$ & 5.97 & 2.14 to 16.69 & 0.001 \\
\hline HMW latex antigens & $114 / 1134$ & 1.32 & 1.29 & 0.99 to 1.67 & 0.060 & 0.142 & $20 / 972$ & 1.23 & 0.67 to 2.26 & 0.503 \\
\hline HMW bioaerosol antigens & $19 / 311$ & 0.77 & 1.09 & 0.65 to 1.81 & 0.749 & 0.864 & $4 / 259$ & 1.14 & 0.38 to 3.41 & 0.818 \\
\hline HMW pharmaceutical product antigens & $0 / 5$ & - & - & - & - & & - & - & - & - \\
\hline \multicolumn{11}{|l|}{ Low molecular weight } \\
\hline LMW highly reactive chemicals & $74 / 809$ & 1.19 & 1.33 & 0.98 to 1.79 & 0.067 & 0.142 & $13 / 670$ & 1.23 & 0.61 to 2.48 & 0.555 \\
\hline LMW reactive chemicals-isocyanates & $11 / 188$ & 0.73 & 1.04 & 0.54 to 1.98 & 0.911 & 0.936 & $4 / 159$ & 1.91 & 0.63 to 5.79 & 0.253 \\
\hline LMW reactive cleaning/disinfecting products & $92 / 755$ & 1.63 & 1.67 & 1.26 to 2.22 & 0.000 & 0.000 & $20 / 627$ & 1.91 & 1.03 to 3.56 & 0.041 \\
\hline LMW antigenic wood dusts & $21 / 269$ & 1.00 & 1.49 & 0.91 to 2.45 & 0.115 & 0.173 & $1 / 222$ & - & - & - \\
\hline LMW metal and metal fume antigens & $50 / 609$ & 1.05 & 1.45 & 1.02 to 2.07 & 0.039 & 0.117 & $14 / 497$ & 2.13 & 1.05 to 4.32 & 0.037 \\
\hline \multicolumn{11}{|l|}{ Mixed environmentst } \\
\hline Mixed environments: metal working fluids exposures & $11 / 189$ & 0.73 & 1.03 & 0.54 to 1.97 & 0.936 & 0.936 & 2/155 & - & - & - \\
\hline Mixed environments: textile production & $32 / 257$ & 1.67 & 1.71 & 1.12 to 2.61 & 0.012 & 0.053 & 9/208 & 2.36 & 1.05 to 5.31 & 0.038 \\
\hline Mixed environments: agricultural antigens & $35 / 399$ & 1.13 & 1.43 & 0.96 to 2.13 & 0.078 & 0.142 & $10 / 338$ & 2.14 & 0.99 to 4.62 & 0.054 \\
\hline
\end{tabular}

Each effect estimate is from a separate model with the reference group being individuals who had always worked in a non-exposed job. Note that the exposure groups are not mutually exclusive and are not adjusted for exposure to any of the other agents in the table.

The $q$ value corresponds to the minimum false discovery rate at which the test may be called significant $(q<0.05)$.

Bold type indicates conventional levels of statistical significance $(p<0.05)$

${ }^{*}$ Adjusted for sex, smoking, father's social class at birth, region and hay fever.

†Those with asthma but no airflow limitation were coded 'no' for this analysis.

HMW, high molecular weight; LMW, low molecular weight; N/A, correction for multiple testing not applied. 
Table 4 Association of adult onset asthma with ever having worked in a low-risk exposure group (with and without a high-risk) by age 42

\begin{tabular}{|c|c|c|c|}
\hline Exposure group & Case/total & $\mathrm{OR}_{-}^{*}$ & $95 \% \mathrm{Cl}$ \\
\hline \multicolumn{4}{|l|}{ Combustion particles/fumes: vehicle/motor exhaust exposure } \\
\hline Reference group (always worked in non-exposed) & $147 / 1864$ & 1.00 & - \\
\hline Exposed to another ASJEM agent but not to combustion particles/fumes & $368 / 4005$ & 1.28 & 1.04 to 1.57 \\
\hline Ever combustion particles/fumes, never a high-risk exposure & $47 / 740$ & 1.09 & 0.77 to 1.56 \\
\hline Ever combustion particles/fumes plus ever a high-risk exposure & $77 / 797$ & 1.65 & 1.21 to 2.24 \\
\hline \multicolumn{4}{|l|}{ Possible exposure to irritants, gases or fumes } \\
\hline Reference group (always worked in non-exposed) & $147 / 1864$ & 1.00 & - \\
\hline Exposed to another ASJEM agent but not to possible irritants, gases or fumes & $272 / 3012$ & 1.28 & 1.03 to 1.59 \\
\hline Ever possible exposure to irritants, gases or fumes, never a high-risk exposure & $66 / 894$ & 1.18 & 0.86 to 1.61 \\
\hline Ever possible exposure to irritants, gases or fumes, plus ever a high-risk exposure & $154 / 1636$ & 1.40 & 1.10 to 1.80 \\
\hline \multicolumn{4}{|l|}{ Environmental tobacco smoke } \\
\hline Reference group (always worked in non-exposed) & $147 / 1864$ & 1.00 & - \\
\hline Exposed to another ASJEM agent but not to environmental tobacco smoke & $387 / 4593$ & 1.27 & 1.03 to 1.56 \\
\hline Ever high probability of exposure to environmental tobacco smoke, never a high-risk exposure & $54 / 465$ & 1.52 & 1.09 to 2.13 \\
\hline Ever high probability of exposure to environmental tobacco smoke, plus ever a high-risk exposure & $51 / 484$ & 1.34 & 0.94 to 1.88 \\
\hline \multicolumn{4}{|l|}{ Low probability of enough exposure for occupational asthma (low antigens) } \\
\hline Reference group (always worked in non-exposed) & $147 / 1864$ & 1.00 & - \\
\hline Exposed to another ASJEM agent but not to low antigens & $202 / 2269$ & 1.32 & 1.05 to 1.66 \\
\hline Ever low antigens, never a high-risk exposure & $127 / 1442$ & 1.34 & 1.03 to 1.73 \\
\hline Ever low antigens, plus ever a high-risk exposure & $163 / 1831$ & 1.26 & 0.99 to 1.60 \\
\hline
\end{tabular}

of exposure to combustion particles or irritant gases and fumes with asthma. There was, however, an association of asthma with exposure to environmental tobacco smoke and exposure to some low level antigens (jobs in occupational environments in which the ASJEM developers considered most workers would have some exposure but this would be too low to produce asthma). Environmental tobacco smoke exposure was dominated by 5123-Waiters, waitresses and bartenders, which was associated with asthma in the occupational code analyses. Low level antigen exposure was given to about 25 occupations (including 5122-Cooks and 5123-Waiters, waitresses, bartenders, shown in table 1 to be occupations at an increased risk of asthma), and many of these occupations were also exposed to other low-risk agents, often 'possible irritants'.

\section{Population attributable fraction}

Table 5 shows the PAF for occupational exposures in this cohort. Overall, exposure to occupational agents in this cohort accounted for $16.3 \%$ (95\% CI $3.8 \%$ to $27.1 \%$ ) of adult onset asthma. There was evidence that those who had ever smoked (55\% of the cohort) were at a higher risk of asthma, and the PAF for smoking was slightly lower than for occupational exposure $(11.2 \%, 95 \%$ CI $2.6 \%$ to $19.1 \%)$.

\section{DISCUSSION}

We have shown that several occupations and occupational exposures are associated with the development of adult onset asthma in adults born in 1958 who have lived and worked in Britain. Unsurprisingly, the strongest associations observed were with occupations (eg, farmers) and exposures (eg, HMW flour, enzyme exposure) that are known to cause asthma. Exposure to low-risk agents was common and often occurred in people who at some point in their life had also been exposed to high-risk agents. Overall, exposure only to low-risk agents was not associated with asthma. However, there was evidence that, in the absence of exposure to high-risk agents, exposure to environmental tobacco smoke and to low levels of antigens (ie, work in jobs considered by the ASJEM expert group to have exposures too low to cause harm) could be associated with asthma.

The strength of this study is that data come from a large population-based sample covering the period of entry to the work force to mid adult life. The cohort has maintained good response rates at each follow-up (>70\%), although a lower proportion have taken part in every follow-up. Non-response has been greater in men, lower educational achievers and those who change employment frequently. ${ }^{16}$ The characteristics of the participants in the biomedical follow-up are broadly representative of individuals born in Britain in $1958,{ }^{16}$ although the

Table 5 Population attributable fraction (PAF) of lifetime occupational exposures for adult onset asthma by age 42

\begin{tabular}{|c|c|c|c|}
\hline Exposure categories & Prevalence* & PAF (\%) & $95 \% \mathrm{Cl}(\%)$ \\
\hline \multicolumn{4}{|l|}{ Considering individual exposures } \\
\hline Non-exposed & $1864(26.3 \%)$ & - & - \\
\hline $\begin{array}{l}\text { Ever a low-risk exposure (but never } \\
\text { a high-risk) }\end{array}$ & $2087(29.4 \%)$ & 4.0 & -1.5 to 9.2 \\
\hline $\begin{array}{l}\text { Ever a high-risk exposure (but never } \\
\text { a low-risk)) }\end{array}$ & 595 (8.4\%) & 3.4 & 0.7 to 6.0 \\
\hline $\begin{array}{l}\text { Worked in both low-risk jobs and in } \\
\text { high-risk jobs }\end{array}$ & $2542(35.9 \%)$ & 8.9 & 2.0 to 15.3 \\
\hline \multicolumn{4}{|l|}{ Considering all exposures combined } \\
\hline $\begin{array}{l}\text { Exposure to any occupation } \\
\text { exposure (low, high or both) }\end{array}$ & $5224(73.7 \%)$ & 16.3 & 3.8 to 27.1 \\
\hline
\end{tabular}


unemployed and ethnic minority groups are underrepresented (many migrants came to the UK after age 16). ${ }^{17}$ This cohort examines a range of health outcomes and it is unlikely that there is substantially increased participation by those who believe their asthma has been caused by their job. The lower response among lower socioeconomic groups may lead to underestimation of the burden (as they are more likely to work in exposed jobs) and may lead to attenuation of risk and reduction in the power to observe associations. Hay fever as a child was more common in participants who had a full occupational history compared with those who are not included in our analysis $(14.4 \%$ vs $12.4 \% ; \mathrm{p}=0.006)$. We do not know the reason for this but, as hay fever is a major risk factor for the development of asthma, it suggests that asthma incidence in the cohort may be higher than in the general population.

The longitudinal design overcomes bias from the 'healthy worker effect' (the tendency of those with asthma to leave jobs that cause or exacerbate their disease) which tends to distort the findings of cross-sectional studies that seek occupational causes of disease. Our observation that people with asthma tended to spend less time in jobs associated with asthma onset suggests that this 'healthy worker effect' is present, and the increased unemployment at age 42 years in those with asthma is consistent with other longitudinal studies. ${ }^{18}$ A further benefit of our study design is that we have been able to account for the 'healthy hire effect' (the tendency of those with allergic disease to avoid entering jobs with high-risk exposures) by adjusting for the presence of childhood hay fever using information collected during childhood. ${ }^{13}$ We observed consistently higher risks associated with working as a cleaner, in jobs likely to include cleaning tasks, and in jobs likely to lead to exposure to LMW cleaning and disinfecting products. There has been growing interest in the role of cleaning in the development of adult asthma over the last decade. ${ }^{19-21}$ The European Community Respiratory Health Survey showed that, in the domestic setting, the regular use of cleaning sprays was associated with the incidence of asthma. Associations were clearly seen in Norway, Switzerland and Italy but there was no obvious association in the English participants. To date there is limited evidence that exposure to cleaning products may be harmful to respiratory health in the UK. ${ }^{5}$

About $16 \%$ of adult onset asthma in this cohort may be attributable to exposure to occupational agents. This estimate is similar to other longitudinal population-based studies ${ }^{82}$ and meta-analyses of population-based studies. ${ }^{12}$ Few of the studies included in previous meta-analyses were UK-based, and there are no longitudinal population-based studies of adult onset asthma in the UK. There is evidence that the incidence of occupational asthma in British men is higher in those aged $>45$ years than in younger age groups, but further assessment of this cohort is required to determine whether the PAF of occupation for asthma is different at older ages. ${ }^{23}$

Assessing occupational exposures in large studies can be simplified by the use of JEMs and the expert judgement step reduces exposure misclassification. ${ }^{12}$ Using the ASJEM to determine occupational exposures also has the advantage of grouping occupations by exposure, increasing the power to detect associations. However disease-specific JEMs can only identify exposures that are already known to be associated with disease, and we may have missed associations with exposures that cause asthma but are not included in this ASJEM. The risk associated with some exposures cannot be mapped precisely onto specific occupations (because exposures are present across multiple occupations, some occupations have multiple exposures and the expert assessment allows individuals within the same occupation to have different exposures). Each approach highlights different aspects of the risks associated with the work environment. By the use of the ISCO-coded occupation, we may have identified novel occupations associated with asthma such as protective services workers and aircraft mechanics. There has been one report that protective services workers may be at an increased risk of asthma, ${ }^{24}$ and one of the co-authors $(\mathrm{JH})$ has cared for aircraft mechanics who develop asthma in the workplace. Due to the limited occupational information, we were unable to identify specific agents which would explain these increased risks.

An advantage of the British 1958 birth cohort is that exclusion of those with childhood asthma was possible using information collected during childhood rather than by adult recall of childhood disease. However, the age of onset of asthma was not obtained until age 42 and, as in many other studies, ${ }^{25}$ this was often inconsistent with information collected in the earlier assessments. For this reason, we relied on the information collected in childhood to exclude childhood asthma and wheezy bronchitis but did not attempt a time-dependent analysis of the incidence of adult asthma in relation to specific jobs or occupational exposures.

Our study is based on individuals born in 1958 and the exposures experiences by this cohort may not be equivalent to those experienced by the current workforce. For example, exposure to environmental tobacco smoke (determined by the ASJEM) was associated with asthma in our study but such exposure in UK workplaces is no longer relevant due to the Smoke-free (Premises and Enforcement) Regulations 2006.

There is no consensus on how information on occupational asthma should be collected in population-based studies. Some studies ask about 'self-reported wheeze or chest tightness at work' $^{26}$ or 'self-reported current occupational asthma'. ${ }^{27}$ To address concern about the reliance of this analysis on the reporting of 'asthma', we examined associations with objective markers of airway obstruction, as has been done in several other studies. ${ }^{28-30}$ Asthma with airway obstruction was less prevalent than 'asthma', but the strength of the associations in general remained similar (or increased). Asthma with airway obstruction may identify more severe asthma, but we cannot rule out the possibility that it may represent other respiratory conditions such as chronic obstructive pulmonary disease.

Associations of disease with occupation may be confounded by other factors related to social class. We adjusted for childhood socioeconomic status by incorporating father's social class at the time of the participant's birth and adjusted for smoking habit. We cannot rule out residual confounding by smoking but, as we can see associations of asthma with exposure to cleaning products and agriculture in those who report they are lifetime non-smokers, it seems unlikely that this is a major influence on our key findings.

\section{CONCLUSIONS}

In this population-based cohort of those born in 1958 followed up to mid adult life, we have corroborated associations with several occupations previously identified as risk factors for asthma in a British population. We have also identified potential new occupations as risk factors for asthma. We have shown that occupations and exposures related to cleaning and other irritant exposures are consistently associated with an increased risk of adult onset asthma and that, overall, occupational exposure accounts for an estimated $16 \%$ of disease. The findings of this study are the first of their kind in the UK and provide valuable information for those concerned with reducing the incidence of asthma in adult life. 
Acknowledgements We wish to acknowledge the original creators, sponsors, depositors and distributors of the NCDS data. Sweeps 0-3, 1958-1974 were created by the National Birthday Trust Fund and the National Children's Bureau and sponsored by the Economic and Social Research Council, the National Birthday Trust Fund, the Institute of Child Health (University College London), the National Foundation for Educational Research and the Department of Health. Sweep 4, 1981 and Public Examination Results, 1978 were created by the National Children's Bureau and sponsored by the Department of Health and Social Security, the Department of Education and Science, the Department of Employment, the Department of the Environment and the Manpower Services Commission. Sweep 5, 1991 was created by the Social Statistics Research Unit, City University and sponsored by the Economic and Social Research Council, the Department of Health, the Department of Social Security, the Department of Employment, the Department of Education and Science, the Department of the Environment, the Transport and Road Research Laboratory, the Health and Safety Executive and the National Institute for Child Health and Development, USA. The principal investigator (depositor and copyright holder) for all three Data Collections is the Centre for Longitudinal Studies, Institute of Education, University of London. The Data Collections (2nd edition, 2008) were distributed by the UK Data Archive, University of Essex, Colchester. The original data creators, depositors or copyright holders, the funders of the Data Collections and the UK Data Archive bear no responsibility for their further analysis or interpretation.

Contributors DJ, DPS and PC conceived and designed the original research. REG prepared and analysed the data with support and supervision from DJ and PC. REG and DJ prepared and drafted the original manuscript. BKB provided statistical advice, comments and interpretation. DPS commented on drafts and provided additional interpretation. JH, DF, PC and CJW assisted with the occupational coding, exposure assignment and provided additional comments and interpretation. All authors approved the final manuscript.

Funding Asthma UK provided funding for the first 2 years of the project and the COLT Foundation funded 15 months of R Ghosh's PhD. Neither had any role in conducting the study.

Competing interests None.

Ethics approval ACCC or CDAC Oversight Committee.

Provenance and peer review Not commissioned; internally peer reviewed.

Data sharing statement The data used are available upon application for non-commercial research purposes at http://www2.le.ac.uk/projects/birthcohort/ 1958BC-About/application-procedures. The use of the biomedical data requires a separate application. The occupational data created for this study will be returned to the 1958 birth cohort and made available to researchers after publication.

\section{REFERENCES}

1 Toren K, Blanc P. Asthma caused by occupational exposures is common-a systematic analysis of estimates of the population-attributable fraction. BMC Pulm Med 2009;9:7.

2 Blanc PD, Toren K. How much adult asthma can be attributed to occupational factors? Am J Med 1999;107:580-7.

3 Le Moual N, Kauffmann F, Eisen EA, et al. The healthy worker effect in asthma: WORK may cause asthma, but asthma may also influence work. Am J Respir Crit Care Med 2008;177:4-10.

4 Meyer JD, Holt DL, Chen Y, et al. SWORD '99: surveillance of work-related and occupational respiratory disease in the UK. Occup Med 2001;51:204-8.

5 Health and Safety Executive. Table THORR06: Occupational asthma: number of diagnoses in which particular causative substances were identified 2008-2010. 2011. http://www.hse.gov.uk/statistics/tables/index.htm\#top (accessed 19 Apr 2012).

6 Health and Safety Executive. Occupational asthma. 2011. http://www.hse.gov.uk/ statistics/causdis/asthma/asthma.pdf (accessed 19 Apr 2012).
7 Burge C, Moore V, Robertson A, et al. Shield Report 2010. 2011. Birmingham, Occupational Lung Disease Unit, Heartlands Hospital. http://www.occupationalasthma. com/occupational_asthma_pageview.aspx?id=4514 (accessed 24 Feb 2012).

8 Kogevinas M, Zock JP, Jarvis D, et al. Exposure to substances in the workplace and new-onset asthma: an international prospective population-based study (ECRHS-II). Lancet 2007;370:336-41.

9 Atherton K, Fuller E, Shepherd P, et al. Loss and representativeness in a biomedical survey at age 45 years: 1958 British birth cohort. J Epidemiol Community Health 2008;62:216-23.

10 Fuller E, Power C, Shepherd P, et al. Technical report on the National Child Development Study biomedical survey 2002-2004. 2006. http://www.cls.ioe.ac.uk/ library-media\%5Cdocuments\%5CNCDS\%20biomed\%20technical\%20report.pdf (accessed 17 Aug 2012).

11 International Labour Office. International Standard Classification of Occupations: ISCO-88. 1990. Geneva: International Labour Organization. http://www.ilo.org/ public/english/bureau/stat/isco/isco88/index.htm

12 Kennedy S, Le Moual N, Choudat D, et al. Development of an asthma specific job exposure matrix and its application in the epidemiological study of genetics and environment in asthma (EGEA). Occup Environ Med 2000;57:635-41.

13 Butland BK, Ghosh R, Strachan DP, et al. Job choice and the influence of prior asthma and hay fever. Occup Environ Med 2011;68:494-501.

14 Newson RB. Frequentist q-values for multiple-test procedures. Stata J 2010;10:568-84

15 Greenland S, Drescher K. Maximum likelihood estimation of the attributable fraction from logistic models. Biometrics 1993;49:865-72.

16 Hawkes D, Plewis I. Modelling non-response in the National Child Development Study. J R Statist Soc 2006;169:479-91.

17 Plewis I, Calderwood L, Hawkes D, et al. Changes in the NCDS and BCS70, Populations and Samples over Time. Centre for Longitudinal Studies, Institute of Education, University of London 2004. http://www.esds.ac.uk/doc/5579/mrdoc/pdf/ ncds_and_bcs70_response.pdf (accessed 17 Aug 2012).

18 Thaon I, Wild P, Mouchot L, et al. Long-term occupational consequences of asthma in a large French cohort of male workers followed up for 5 years. Am J Ind Med 2008;51:317-23.

19 Jaakkola JJ, Jaakkola MS. Professional cleaning and asthma. Curr Opin Allergy Clin Immunol 2006:6:85-90.

20 Rosenman KD, Reilly MJ, Schill DP, et al. Cleaning products and work-related asthma. J Occup Environ Med 2003;45:556.

21 Medina-Ramon M, Zock JP, Kogevinas M, et al. Asthma, chronic bronchitis, and exposure to irritant agents in occupational domestic cleaning: a nested case-control study. Occup Environ Med 2005;62:598-606.

22 Eagan T, Gulsvik A, Eide GE, et al. Occupational airborne exposure and the incidence of respiratory symptoms and asthma. Am J Respir Crit Care Med 2002;166:933-8

23 McDonald JC, Keynes HL, Meredith SK. Reported incidence of occupational asthma in the United Kingdom, 1989-97. Occup Environ Med 2000;57:823-9.

24 Syamlal G. Prevalence of lifetime asthma and current asthma attacks in U.S working adults: an analysis of the 1997-2004 National Health Interview Survey data. J Occup Environ Med 2009;51:1066-74.

25 Burgess JA, Walters EH, Byrnes GB, et al. who remembers whether they had asthma as children? J Asthma 2006;43:727-30

26 Blanc PD, Trupin L, Eisner M, et al. The work impact of asthma and rhinitis: findings from a population-based survey. J Clin Epidemiol 2001;54:610-18.

27 Blanc PD. Occupational asthma in a national disability survey. Chest 1987;92:613-17

28 Krzyzanowski M, Kauffmann F. The relation of respiratory symptoms and ventilatory function to moderate occupational exposure in a general population. Int J Epidemiol 1988; 17:397-406.

29 de Meer $\mathrm{G}$, Kerkhof $\mathrm{M}$, Kromhout $\mathrm{H}$, et al. Interaction of atopy and smoking on respiratory effects of occupational dust exposure: a general population-based study. Environ Health 2004;3:6.

30 Le Moual N, Kennedy SM, Kauffmann F. Occupational exposures and asthma in 14000 adults from the general population. Am J Epidemiol 2004;160:1108-16. 